\title{
STUDY OF RELATIONSHIP BETWEEN FEAR OF FALLING \& ABILITY TO SIT ON \& RISE FROM THE FLOOR IN ELDERLY POPULATION
}

\section{Pooja Samant, Venu Mohan *, Ashok Shyam, Parag Sancheti.}

Sancheti Institute College of Physiotherapy, Pune, Maharashtra, India.

\section{ABSTRACT}

Background: Falls has been well established as one of the leading causes of mortality and morbidity among older adults. Falling in elderly persons can lead to disability, hospitalizations, and premature death. It can also lead to reduced levels of independence, poorer quality of life, and high levels of anxiety. It is proven that the elderly develop a fear of fall (FOF) due to the above mentioned consequences. They develop FOF with or without the history of fall. Increasing age is a significant predictor of FOF. FOF thus cause restriction in social participation and also restrictions in activities of daily living ( $A D L)$. Sitting on the floor is a tradition or a habit of Indians during activities like eating, praying, socializing etc., thus making it an important ADL. Thus, sitting and rising from the floor is a basic functional task for Indian population. The inability to sit and get up from the floor is closely related to the risk of falling, and if a fall has occurred, the capacity to return to an upright position is critical.

Materials and Methods: The study included 210 community dwelling elderly population of an age group of 60-90 yrs, with an ability to sit on and get up from the floor. Individuals with any musculoskeletal, cardiorespiratory and neurological conditions were excluded. A physical assessment was done which included two tests. 1. Falls Efficacy Scale - International (in hindi) to assess fear of fall 2. Sitting Rising Test (SRT) to assess the ability to sit on and get up from the floor. A partial correlation analysis was conducted to find a relationship between Fear of Fall and the ability to sit on the floor after controlling for age. Alpha level is set as 0.05 . Spearman's rho test was used.

Result: According to Spearman's Rho's Test of Correlation, Correlation between Fall Efficacy Scale - International \& Sitting - Rising Test is -0.352 . Thus showing that there is a Low Negative Correlation between the Fear of Fall and Ability to Sit on and Get up From the Floor.

Conclusion: There is a relationship between Fear of Fall and the ability to sit on and get up from the floor in the elderly population.

KEY WORDS: Fear of fall, Sitting on the floor, Falls Efficacy Scale - International, Sitting Rising Test, Elderly Population.

Address for correspondence: Dr. Venu Mohan (PT), Sancheti Institute College of Physiotherapy, Pune-411005, Maharashtra, India. E-Mail:venumohan@gmail.com

Access this Article online

Quick Response code

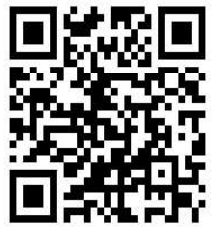

DOI: $10.16965 /$ ijpr.2019.148

Journal Information

International Journal of Physiotherapy and Research

ICV for 2016 ISSN (E) 2321-1822 | ISSN (P) 2321-8975

86.93 https://www.ijmhr.org/ijpr.html DOI-Prefix: https://dx.doi.org/10.16965/ijpr (cc) BY-Mt-Bi

Article Information

Received: 26 Apr 2019

Peer Review: 29 Apr 2019

Revised: None
Accepted: 09 Jun 2019

Published (O): 19 Aug 2019

Published (P): 19 Aug 2019

\section{BACKGROUND}

Falls has been settled as one of the primary reasons for the increased mortality rates amongst the elderly. Falling in elderly persons can lead to incapacity, cost-consuming hospitalization, and early death. All such factors may result in increased levels of dependency, reduced quality of life and greater level of anxiety [1].
Haven had a history of falling or not, it is proven that the elderly develops a Fear of Fall due to the above-mentioned reasons. Thus, Fear of Fall (FOF) is an important factor to be predicted with increasing age. FOF thus limits the elderly to engage in social activities and also cause an impediment in performing activities of daily living (ADL) [2]. 
It is observed that, sitting on the floor as a tradition or habit, is a basic functional task, especially for the Indians, and thus is a preferred position for people of all age groups. This position is used for both, Basic Activities of daily living, like eating, bathing, using the toilets, etc. as also for Instrumental activities of daily living household or any other occupation-related chores. It is also used for praying or performing religious rituals or just socializing. The older population especially in rural or poorer homes, predominantly prefer sitting on the floor to perform such activities [3]. If a fall has occurred the ability of a getting up from that position on the floor is crucial to avoid associated ricks and to minimize damage.

The inability to sit and get up from the floor is closely related to the risk of falling, and if a fall has occurred, the incapacity to return to an upright position is harmful $[4,5]$.

The sitting-rising test (SRT) is a straightforward test with high reliability, which was created to assess the capacity to sit and ascend from the floor. The SRT evaluates the number of supports (i.e., hand or knee) required and thus, judge the stability in the activities performed while sitting down on and while getting up from the floor. 10 is the maximum score, and points are deducted for using extra hand support or instability [5].

AIM: To find out if ability to sit on and rise from the floor is a contributing factor for prevalence of fear of fall in the Elderly Population.

OBJECTIVE: 1 . To assess the Fear of Fall in elderly population. 2 . To assess ability sit on the floor by SRT. 3. To compare the above two results for studying their relationship.

\section{MATERIALS AND METHODS}

Study Design: Cross Sectional Study

Sampling Technique: Purposive Sampling

Study Population: The age group was 60 to 90 years. Community dwelling elderly population was chosen. All subjects were able to stand up from the floor and sit on the floor with or without support.

People having conditions like: Cognitive impairment, any Respiratory, Cardiovascular, Neurological or any other debilitating conditions, any acute or chronic injuries were excluded.

\section{Sample Size: 210}

\section{Assessment:}

Falls Efficacy Scale and Sitting-Rising Test and the other measurements mentioned before are assessed.

After getting an approval from the ethical committee written consent was taken from the participants for the study. Consent form was given to the subject for their participation in the study. The patients were included according to the inclusion criteria. The patients were selected in the control or experimental group by convenient sampling.

Physical Measurements and Outcome Measures taken were:

1. Falls Efficacy Scale (FES) (Hindi Version) score to assess Fear of Fall [7].

2. Sitting-rising test (SRT) - to asses to ability to sit on and get up from the floor [5].

Statistics: After Evaluation form was filled with the obtained values, Data Analysis was done. A partial correlation analysis was conducted find a relationship between Fear of Fall and the ability to sit on the floor after controlling for age. Alpha level was set as 0.05 . Spearman's rho test was used.

\section{RESULT}

Data analysis: According to Spearman's Rho's Test of Correlation, Correlation between Fall Efficacy Scale - International \& Sitting - Rising Test is $\mathbf{- 0 . 3 5 2}$. Thus showing that there is a Low Negative Correlation between the Fear of Fall and Ability to Sit on and Get up From the Floor.

\begin{tabular}{|c|c|c|}
\hline & Mean & $\begin{array}{c}\text { Standard } \\
\text { Deviation }\end{array}$ \\
\hline AGE & 70.312 & 6.7 \\
\hline $\begin{array}{c}\text { FES-I Score } \\
\text { (out of 64) }\end{array}$ & 33.27 & 8.07 \\
\hline $\begin{array}{c}\text { Sitting-Rising Test Score } \\
\text { (out of 10) }\end{array}$ & 4.64 & 1.21 \\
\hline
\end{tabular}

\section{DISCUSSION}

Many studies have reported the prevalence of relationship between Fear of Fall and functional mobility and balance. In this study that Fear of Fall is correlated with the ability to sit on and get up from the floor in the elderly population. The rationalization for this can be: Diminished postural control in the elderly population: Poor 
postural performance can be due to decreased strength of the musculature in the elderly, reduced maintenance of balance which may cause increased level of anxiety in them, in turn leading to loss of confidence while performing ADLs. These factors do not occur exclusively; rather they co-exist and act in an additive manner to reduce the postural control [9]. Another reason for this could be, modification of lifestyle: Adaptation to the Western lifestyle, may cause decrease the chances of sitting on the floor [1]. Also, Limitation of ADLs could be a reason as Fear of fall is proved to cause restrictions in ADLs, sitting on the floor being an important position for performing ADLs, is difficult to achieve and thus, furthermore reducing the range of ADLs in the elderly [1].

As we have achieved a Negative Correlation Between FES-I \& SRT, we can say the ability of the Elderly Population to sit and get up from the floor is lesser in individuals having greater fear of fall. But according to the results there is Low negative coefficient of correlation is obtained, suggesting that though there exists a correlation between these two factors, it may not be as significant. Although low negative, the correlation obtained through this research is taken into consideration while planning physical therapy program in the elderly. The basis of treatment of the elderly population who have low level of confidence while performing ADLs due to Fear of Fall should be on how to increase the daily activities in a proficient way and development of self-efficacy by decreasing the amount of fear in them. These treatment strategies may and also can be used to improve the ability of the elderly to sit on and get up from the floor, owing to its earlier mentioned importance in them.

\section{CONCLUSION}

In this study, a relationship between Fear of Fall and Ability to sit on and get up from the floor was obtained, suggesting that though to a smaller extent, there is an association between an elderly individual's ability to sit on and get up from the floor and the fear of fall experienced by him/her. Thus maintaining this ability can avert the fear of falling and improve the quality of life of the elderly.

\section{ACKNOWLEDGEMENTS}

We take this opportunity to thank Dr. Dhara Kapoor and Dr. Rachana Dabadghav (Research Co-ordinator at Sancheti Institute College of Physiotherapy) for their valuable guidance and constant encouragement that motivated me to complete this study. We extend our gratitude to all the teachers who co-operated and participants of the study who voluntarily participated in the study.

\section{Conflicts of interest: None}

\section{REFERENCES}

[1]. Yardley L, Smith H. A prospective study of the relationship between feared consequences of falling and avoidance of activity in community-living older people. The Gerontologist. 2002 Feb 1;42(1):17-23.

[2]. Arfken CL, Lach HW, Birge SJ, Miller JP. The prevalence and correlates of fear of falling in elderly persons living in the community. American journal of public health. $1994 \mathrm{Apr} ; 84(4): 565-70$..

[3]. Nagrajan A, D'Souza SA. Using the Newly Developed Floor-Sitting Movement Analysis Proforma to Study the Effect of Age and Activity on Floor-Sitting in Indian Adults. Journal of cross-cultural gerontology. 2017 Mar 1;32(1):71-93.

[4]. Tinetti ME, Liu WL, Claus EB. Predictors and prognosis of inability to get up after falls among elderly persons. Jama. 1993 Jan 6;269(1):65-70.

[5]. Nomura T, FUTAKI T. Preliminary study of the relationship between fear of falling and ability to sit on the floor. Journal of Physical Education and Medicine. 2010;11(1):19-26.

[6]. Brito LB, de Araújo DS, de Araújo CG. Does flexibility influence the ability to sit and rise from the floor?. American journal of physical medicine \& rehabilitation. 2013 Mar 1;92(3):241-7.

[7]. de Brito LB, Ricardo DR, de Araújo DS, Ramos PS, Myers J, de Araújo CG. Ability to sit and rise from the floor as a predictor of all-cause mortality. European journal of preventive cardiology. 2014 Jul;21(7):892-8.

[8]. Arora P. Reliability and validity of the Hindi version of Falls Efficacy Scale-International (FES-I) among older adults in Alberta.

[9]. Maki BE, Holliday PJ, Topper AK. Fear of falling and postural performance in the elderly. Journal of gerontology. 1991 Jul 1;46(4):M123-31.

How to cite this article: Pooja Samant, Venu Mohan, Ashok Shyam, Parag Sancheti. STUDY OF RELATIONSHIP BETWEEN FEAR OF FALLING \& ABILITY TO SIT ON \& RISE FROM THE FLOOR IN ELDERLY POPULATION. Int J Physiother Res 2019;7(4):3181-3183. DOI: 10.16965/ijpr.2019.148 